\title{
Sympathetic chain clipping for hyperhidrosis is not a reversible procedure
}

\author{
Christoph H. Schick • Georg Bischof • Alan A. E. P. Cameron • Cliff P. Connery • \\ J Ribas M. de Campos • Moshe Hashmonai - Peter B. Licht
}

Received: 24 August 2012/Accepted: 11 January 2013/Published online: 8 February 2013

(C) Springer Science+Business Media New York 2013

Sympathetic chain clipping for hyperhidrosis is not a reversible procedure. We compliment Dr. Loscertales et al. [1] for their excellent study, a very important addendum to our scientific knowledge of sympathetic ablation for the treatment of primary hyperhidrosis $(\mathrm{HH})$. Blocking the sympathetic chain by clipping in patients with $\mathrm{HH}$ has been used for several years, in the belief that if intolerable compensatory hyperhidrosis $(\mathrm{CHH})$ develops, unclipping allows reversal. Several clinical studies have been published that report a variable degree of reduction in CHH. In some of the "successful" reversals, palmar HH did not recur. One should bear in mind that the pressure exercised by a clip is reported to be enormous. In a study on the required burst pressures for a clip to slip from the vessel on

This study was conducted on behalf of the International Society of Sympathetic Surgery (ISSS)

C. H. Schick

German Hyperhidrosiscentrum, Munich, Germany

G. Bischof

St Josef Krankenhaus, Vienna, Austria

\author{
A. A. E. P. Cameron \\ Ipswich, UK \\ C. P. Connery \\ St Luke's-Roosevelt Hospital, New York, NY, USA \\ J. R. M. de Campos \\ Hospital Israelita Albert Einstein, Sao Paulo, Brazil \\ M. Hashmonai $(\bowtie)$ \\ Technion-Israel Institute of Technology, Haifa, Israel \\ e-mail: hasmonai@inter.net.il \\ P. B. Licht \\ Odense University Hospital, Odense, Denmark
}

which it was applied, values of 593-854 mmHg were needed [2]. Removal of a clip by pulling should by itself tear the encompassed tissue. Therefore, the puzzling aspects of the clinical results that have been published are not the failures, but the allegedly successful cases. The results of Dr. Loscertales et al. study further confirm this incompatibility. How can we explain the allegedly successful clinical reports? The pathophysiology of $\mathrm{CHH}$ is absolutely obscure. It is possible that unclipping exercises an important placebo effect. This is plausible, especially for those patients in whom recurrent $\mathrm{HH}$ is not observed. Is reoperation to remove applied clips justifiable in the light of current knowledge? The answer may be negative, and patients who are advised to have the clips removed should at least be informed that the basis for the offer is empirical and has no proven scientific ground. Further experimental studies are required to prove that in the long-term, there is no nerve regrowth through the clipped segment of the sympathetic chain.

Disclosures Christoph H. Schick, Georg Bischof, Alan A.E.P. Cameron, Cliff P. Connery, J Ribas M. de Campos, Moshe Hashmonai, and Peter B. Licht have no conflict of interest or financial ties to disclose

\section{References}

1. Loscertales J, Congregado M, Jimenes-Merchan R, Gallardo G, Trivino A, Moreno S, Loscertales B, Galera-Ruiz H (2012) Sympathetic chain clipping for hyperhidrosis is not a reversible procedure. Surg Endosc 26:1258-1263

2. Harold KL, Pollinger H, Matthews BD, Kercher KW, Sing RF, Heniford BT (2003) Comparison of ultrasonic energy, bipolar thermal energy, and vascular clips for the hemostasis of small-, medium-, and large-sized arteries. Surg Endosc 17:1228-1230 